\title{
Association Between Obesity and Sarcoidosis: A Systematic Review and Meta-analysis
}

\author{
David Wainaina Wambui ${ }^{1, *}$, Ogugua Ndili Obi ${ }^{2}$, Gregory Dale Kearney ${ }^{1}$ \\ ${ }^{1}$ Department of Public Health, Brody School of Medicine, East Carolina University, Greenville, USA \\ ${ }^{2}$ Department of Internal Medicine, Division of Pulmonary, Critical Care and Sleep Medicine, Brody School of Medicine, East Carolina \\ University, Greenville, USA
}

Email address:

wambuid18@students.ecu.edu (D. W. Wambui), obio@ecu.edu (O. N. Obi), kearneyg@ecu.edu (G. D. Kearney)

${ }^{*}$ Corresponding author

\section{To cite this article:}

David Wainaina Wambui, Ogugua Ndili Obi, Gregory Dale Kearney. Association Between Obesity and Sarcoidosis: A Systematic Review and Meta-analysis. American Journal of Internal Medicine. Special Issue: Occupational and Environmental Lung Diseases: The Emergency Global Health Threats. Vol. 8, No. 5, 2020, pp. 237-245. doi: 10.11648/j.ajim.20200805.18

Received: August 7, 2020; Accepted: August 28, 2020; Published: September 7, 2020

\begin{abstract}
Background: Sarcoidosis is a systemic inflammatory disease characterized by epithelioid granuloma formation in various organs. The etiology of sarcoidosis is unknown. Several studies report an increased risk of sarcoidosis in obese patients The purpose of this study is to conduct a systematic review to assess the risk of sarcoidosis in obese or overweight patients, and to provide a population-based estimate of the risk of sarcoidosis in obese and overweight individuals. Methods: Using the Preferred Reporting Items for Systematic Review and Meta-analysis Protocols (PRISMA) guidelines, we conducted a comprehensive search of studies (Randomized control trial (RCT), cohort or case-control) studies that estimated the risk of sarcoidosis with body mass index (BMI) between 2009-2019 using keywords and MESH terms related to obesity and sarcoidosis. The search was conducted in MEDLINE, EBSCO, and CINAHL. Three independent investigators reviewed each article and assessed for bias. Data was extracted from each study that met inclusion criteria. Quantitative analysis was performed using Review Manager 5.3 software. Results: An initial search yielded 77 potential articles; 73 articles did not meet inclusion criteria and 4 were included in the final analysis. The pooled risk estimate for the incidence of sarcoidosis in obese and overweight individuals was 1.68 [95\% confidence interval 1.5-1.87] with a significant statistical heterogeneity, $\mathrm{I}^{2}$ of $92 \%$. Conclusion: From our systematic review, obese and overweight individuals have a 68\% (RR 1.68, 95\% CI 1.50 to 1.87) increased risk of developing sarcoidosis in comparison with normal or underweight individuals. More studies are needed to further evaluate the role of obesity in the etiopathogenesis of sarcoidosis.
\end{abstract}

Keywords: Sarcoidosis, Obesity, Pulmonary

\section{Introduction}

The incidence of obesity is increasing worldwide [1-3] and has been associated with an increasing incidence of autoimmune diseases including rheumatoid arthritis, psoriasis, Lupus and autoimmune thyroiditis. [4-10]. The World Health Organization (WHO) has defined obesity as a Body Mass Index $(\mathrm{BMI}) \geq 30 \mathrm{~kg} / \mathrm{m}^{2}$ and overweight as BMI $\geq 25 \mathrm{Kg} / \mathrm{m}^{2}$ to $<30 \mathrm{~kg} / \mathrm{m}^{2}$ [11] In 2015 , over $40 \%$ of the world's adult population was overweight and about 13\% (over 600 million people) were obese. $[1,2]$ In $2015-2016,38 \%$ of US men and $41.5 \%$ of US women were considered obese. [12] The prevalence of obesity in the US varies by race, ethnicity and geography. Hispanics and non-Hispanic blacks have the highest age-adjusted prevalence rates of obesity in the US. [12] Geographically, the western states have the lowest prevalence rates of obesity in the country. [13]

Sarcoidosis is a systemic granulomatous inflammatory disease of unknown etiology characterized by non-caseating granulomas which can affect any organ in the body. $[14,15]$ It involves the lungs in over $90 \%$ of cases. [14-16] The incidence of sarcoidosis varies with race, gender and geographic location. [17-20] Worldwide, the highest incidence rates of sarcoidosis are reported in Northern Europe and in the United States. [17, 21] In the US, the 
incidence of disease is 2 to 3 times higher in African Americans than in Whites. [19, 20] Geographically in the US the northeastern states have the highest incidence of disease while the western states have the lowest rates. [20] This geographic variability maybe attributed to various environmental exposures thought to be associated with sarcoidosis [22, 23] however, it is also notable, that the geographic distribution of sarcoidosis in the US mimics that of obesity very closely. [13, 20]

The etiology of sarcoidosis is unknown. However, it has been hypothesized that genetic predisposition, occupational/environmental exposures and infection with certain bacterial antigens may play a role in the etiopathogenesis of disease. [24-26] More recently, obesity has been implicated as a risk factor in the etiology of sarcoidosis. [5, 27-31] Harpsøe et al [5] evaluated a prospective cohort of over 75,000 Danish women enrolled in the Danish National Birth Cohort during 1996 - 2002 [5, 32] and found that obese women had a 3.59 fold (HR 3.59, 95\% CI 2.31 to 5.57) increased risk of developing sarcoidosis than their non-obese counterparts. Subsequently, Cozier et. al [28] using data from the Black Women's Health Study (BWHS), a longitudinal follow-up study of 59,000 US black women aged 21 to 69 years at baseline found that there was a $42 \%$ (IRR 1.42, 95\% CI 1.07-1.89) increased incidence of sarcoidosis for black/African American women with BMI $\geq$ $35 \mathrm{Kg} / \mathrm{m}^{2}$ at study baseline compared to non-obese subjects. That study also showed that significant weight gain between age 18 and study baseline (median age 38 years), was associated with an increased risk of sarcoidosis. Subjects who gained $30 \mathrm{~kg}$ or more between age 18 and study entry, had a $47 \%$ (IRR 1.47, 95\% CI 1.10-1.97; p trend 0.16) increased risk of developing sarcoidosis. [28] Two additional epidemiological studies done in predominantly white US populations showed similar results. [30, 31] Dumas et. al. followed over 110, 000 predominantly white female nurses enrolled in the Nurses Health Study II (NHSII) [31] from 1989 - 2013 and found that subjects who were overweight (BMI 25-29.9) at study entry had a 53\% (HR 1.53, 95\% CI 1.12-2.10) increased risk of incident sarcoidosis while subjects who were obese at study entry had a 74\% (HR 1.74, 95\% CI 1.26-2.40) increased risk of developing sarcoidosis.

Both the BWHS and the NHSII had broad subject representations in the USA, and enrolled patients in over 14 US states with representations across the four geographic regions. [33, 34] A case control study done in Olmsted county $\mathrm{MN}$ (predominantly White population) compared patients diagnosed with sarcoidosis over a 37-year period from 1976 to 2013 to age and gender matched controls from the same population, and found a $12 \%$ increased odds of developing sarcoidosis in overweight subjects (OR 1.12; 95\% CI $0.72-1.75$ ) and a 2.5 fold increased odds (OR 2.54, 95\% CI $1.58-4.06)$ of developing sarcoidosis in obese subjects. [30]

These studies were done in very select populations (Black females [28], White females [31], Danish women [5, 32], Olmsted County, MN [30]) and a generalizable population- based risk estimate for the incidence of sarcoidosis in obese subjects is not available. The aim of this study was to further evaluate the incidence of sarcoidosis in obese subjects with a goal of providing a generalizable population-based risk estimate of disease. This primary aim of this study was to review the current literature to evaluate the association between high BMI ( $>25)$ and the risk of sarcoidosis. The goal is to provide a population-wide risk estimate of disease in overweight and obese subjects.

\section{Methods}

\subsection{Search Strategy}

A comprehensive search of published literature was conducted in MEDLINE, EBSCO, CINAHL and EMBASE databases. The search strategy was restricted to published literature within the past 10 years (January 2009 to September 2019) and available in English language. A hand search of other relevant literature from references of relevant articles was also performed.

\subsection{Inclusion Criteria}

Inclusion criteria included studies that had the following 1) Randomized Control Trials, Cohort or case-control studies with a well described effect measure that described the risk of developing sarcoidosis based on body weight or BMI. 2) Well defined sarcoidosis cases in line with acceptable international disease-classification codes. For case-control studies, cases must have been matched with the controls on various demographics of importance such as age, race and gender. Matching was important because the incidence and clinical presentation of sarcoidosis has been shown to vary with race, age, gender and geo-ethnicity. [16, 19, 20, 35-40] Eligible studies included in this review were independently reviewed and determined by the three investigators. In case of disagreements, a consensus was built to resolve them.

\subsection{Data Extraction}

A systematic data extraction form as provided by the PRISMA statement was used to extract important information from the selected articles. The information collected included 1) article title 2) authors 3) publication year 4) study participants 5) average follow-up time 6) effect of outcome measure and 7) estimated risk or odds ratio. To ensure objectivity, this process was supervised by the senior author. The study was exempted from IRB review since it involved review of secondary data.

\subsection{Statistical Analysis}

Quantitative data analysis was performed using Review Manger (v5.3) software from the Cochrane Collaboration (London, UK). Cases among obese (BMI $>=30)$ or overweight $\mathrm{BMI}>=25$ to $<30$ ) individuals and those among normal (BMI 18.5-24.9) or underweight individuals (BMI $<18.5$ ) were extracted from individual articles. Relative risk 
ratios and weights were computed for individual studies and a pooled estimate was calculated. Cochrane $\mathrm{Q}$ test and a test of heterogeneity $\left(\mathrm{I}^{2}\right)$ test were performed.

\section{Results}

Our search yielded 75 articles as shown in the PRISMA flow diagram in Figure 1. The search on databases yielded 64 potential articles. Search from other sources including review of references in some key papers yielded another 13 articles. After excluding two duplicated articles, there were 75 articles that went through initial review of relevant titles and abstracts. This initial review excluded 62 articles that did not meet the standards of our inclusion criteria. Some of these studies were case reviews or were on other topics on sarcoidosis other than the relationship between obesity and sarcoidosis. 13 articles went under full review after which 9 were excluded since they were either review articles or case reports and were not cohort or case-control studies. Four articles $[5,28,30,31]$ that measured the effect of obesity on the incidence of sarcoidosis satisfied our eligibility criteria and were included in the meta-analysis.

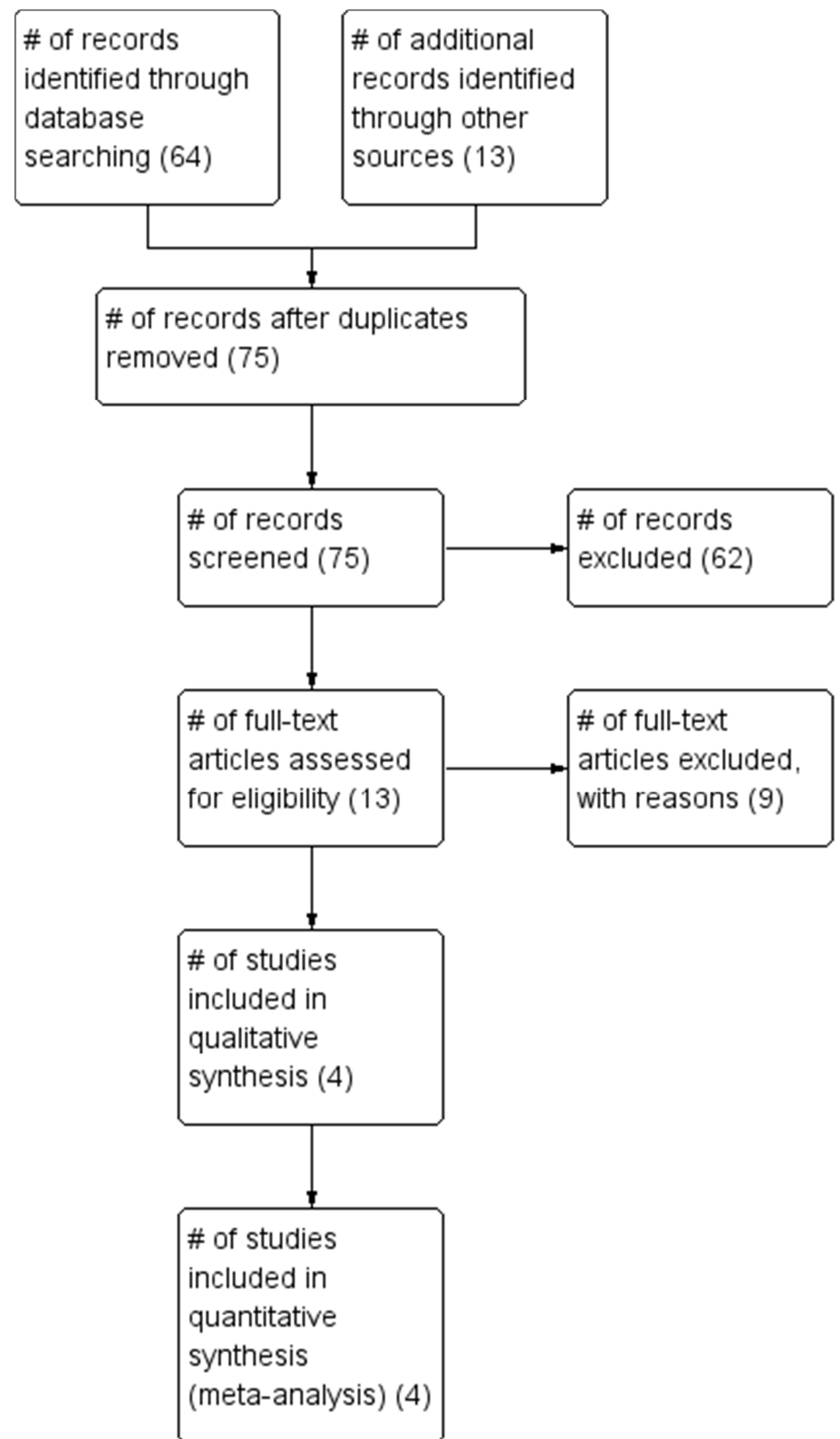

Figure 1. PRISMA flow diagram. 
These studies measured the risk of developing sarcoidosis based on body mass index categorized as underweight, normal weight, overweight and obese. One study [28] included an extra category of morbidly obese subjects with $\mathrm{BMI} \geq 35$ and restricted the group with obesity to BMI 30 to
34 [28]. Two of the studies [28, 31] reported BMI at age 18 as well as baseline BMI at study entry. To be consistent across all four studies, we used only the baseline BMI at study entry for those two studies. The summary of included studies is shown in Table 1.

Table 1. Characteristics of studies included.

\begin{tabular}{|c|c|c|c|c|}
\hline & Harpsøe et al. 2014 [5] & Cozier et al. 2015 [28] & Ungprasert et al. 2016 [30] & Dumas et al. 2017 [31] \\
\hline Study design & Prospective cohort & Prospective cohort & Nested Case-Control & Prospective cohort \\
\hline Publication year & 2014 & 2015 & 2016 & 2017 \\
\hline Case definition & $\begin{array}{l}\text { Sarcoidosis cases were } \\
\text { defined as outlined in the } \\
\text { ICD- } 8 \text { and ICD-10 codes } \\
\text { and physician diagnosis. }\end{array}$ & $\begin{array}{l}\text { Cases were patients who reported being } \\
\text { diagnosed with sarcoidosis in the } \\
\text { preceding } 2 \text { years of a biennial } \\
\text { questionnaire survey. Cases were } \\
\text { validated from patient medical records. }\end{array}$ & $\begin{array}{l}\text { Cases were identified from } \\
\text { diagnostic codes and } \\
\text { confirmation from physician } \\
\text { diagnosis. }\end{array}$ & $\begin{array}{l}\text { Cases were identified from } \\
\text { self-reported physician } \\
\text { diagnosed sarcoidosis. }\end{array}$ \\
\hline Year (s) of study & 1996 to 2002 & 1995 to 2011 & 1976 to 2013 & 1989 to 2013 \\
\hline Follow-up period & 11.4 years & 16 years & *16 years & 24 years \\
\hline Number of Cases & 140 & 454 & 345 & 270 \\
\hline Number of Controls & - & - & 345 & - \\
\hline $\begin{array}{l}\text { Total number in study } \\
\text { population }\end{array}$ & 75,008 & 51,452 & 690 & 116,312 \\
\hline $\begin{array}{l}\text { Average Age (range) at } \\
\text { study enrollment }\end{array}$ & 30.2 years $(27-33)$ & 38 years $(21-69)$ & $* * 45.5$ years $( \pm 13.65)$ & 34 years $(25-44)$ \\
\hline Study Population & $\begin{array}{l}\text { Danish Females enrolled } \\
\text { in the Danish National } \\
\text { Birth Cohort between } \\
1996 \text { to } 2002 \text { [32]. }\end{array}$ & Black Women's Health study [33]. & $\begin{array}{l}\text { Population based cohort study } \\
\text { of residents in Olmsted county } \\
\text { MN diagnosed with sarcoidosis } \\
\text { between } 1976 \text { to } 2013 \text { [82]. }\end{array}$ & $\begin{array}{l}\text { The Nurses Health study II } \\
\text { [34] }\end{array}$ \\
\hline Country & Denmark & USA & USA & USA \\
\hline $\begin{array}{l}\text { Gender and Racial } \\
\text { distribution }\end{array}$ & $\begin{array}{l}\text { White Danish Females } \\
\text { only }\end{array}$ & Black Females only & $\begin{array}{l}50 \% \text { Males; } 91 \% \text { Caucasian, } \\
3 \% \text { AA, } 2 \% \text { Asian, } 3 \% \text { others }\end{array}$ & Females only, $96 \%$ White \\
\hline Age at BMI check & Pre-pregnancy BMI & $\begin{array}{l}\text { BMI at age } 18 \text { and baseline BMI in } \\
1995 .\end{array}$ & $\begin{array}{l}\text { BMI within } 1 \text { year before to } 3 \\
\text { months after date of diagnosis } \\
\text { of sarcoidosis }\end{array}$ & $\begin{array}{l}\text { BMI at age } 18 \text { and baseline } \\
\text { BMI in } 1989 .\end{array}$ \\
\hline $\begin{array}{l}\text { Relative Risk Estimate } \\
(95 \% \mathrm{CI})\end{array}$ & HR: & IRR (for baseline BMI): & OR: & HR (for baseline BMI): \\
\hline BMI $25-29 \mathrm{~kg} / \mathrm{m}^{2}$ & $1.90(1.27-2.84)$ & $1.09(0.85-1.39)$ & $1.12(0.72-1.75)$ & $1.53(1.12-2.10)$ \\
\hline $\mathrm{BMI} \geq 30 \mathrm{~kg} / \mathrm{m}^{2}$ & $3.59(2.31-5.57)$ & $1.24(0.93-1.64)$ & $2.54(1.58-4.06)$ & $1.74(1.26-2.40)$ \\
\hline $\mathrm{BMI} \geq 35 \mathrm{~kg} / \mathrm{m}^{2}$ & - & BMI 30-34: $1.42(1.07-1.89)$ & - & - \\
\hline
\end{tabular}

*computed as an average of the follow up times for cases and controls from table 1 of that paper.

**Mean age reported - computed as the mean of the ages of cases and controls in the paper.

$\mathrm{AA}=$ African American.

Our study included over 243,400 subjects (Table 2). The study population was predominantly female (99\%). The average age of study participants at study enrollment was 36.9 years with an age range of 21 to 69 years. $77 \%$ of the study population were White/Caucasian and 23\% were Black/African American. 63\% had a Low/Normal BMI, $21.9 \%$ were overweight and $14.8 \%$ were obese. For the final analysis, we grouped overweight, obese and morbidly obese subjects together, and underweight and normal weight subjects together. There were 751 cases of incident sarcoidosis in overweight or obese subjects $(0.84 \%)$ and 418 cases of incident sarcoidosis in normal or underweight subjects $(0.27 \%)$.

Table 2. Population characteristics.

\begin{tabular}{ll}
\hline Total Number & N (\%) \\
\hline Total Population Size (N) & 243,462 \\
Average Age in Years (range) & $36.9(21-69)$ \\
Females N (\%) & $243,120(99.9 \%)$ \\
Ethnicity N (\%) & 5 \\
\hline
\end{tabular}

\begin{tabular}{ll}
\hline Total Number & $\mathbf{N}(\mathbf{\%})$ \\
\hline Black/AA & $6,125(23 \%)$ \\
White & $187,295(77 \%)$ \\
Others & $40(<1 \%)$ \\
BMI Categories & \\
Normal/Low & $153,814(63 \%)$ \\
Overweight & $53,329(21.9)$ \\
Obese & $36,142(14.8 \%)$ \\
Unknown & $177(<1 \%)$ \\
\hline
\end{tabular}

As shown in Figure 2 there is an increased risk of developing sarcoidosis among overweight, obese and morbidly obese subjects compared to those who are underweight or have normal BMI. The pooled relative risk estimate was 1.68 [95\% confidence interval, 1.5-1.87]. This suggests that there is a $68 \%$ increased risk of developing sarcoidosis in obese and overweight subjects when compared to their non-obese or underweight counterparts. This was consistent with the findings in the individual studies that were included in the meta-analysis. The included studies showed heterogeneity with an $\mathrm{I}^{2}$ of $92 \%$ which indicates that 
the variation in effect estimates is not by chance.

\begin{tabular}{|c|c|c|c|c|c|c|c|c|c|}
\hline \multirow[b]{2}{*}{ Study or Subgroup } & \multicolumn{2}{|c|}{ Experimental } & \multicolumn{2}{|c|}{ Control } & \multirow{2}{*}{ Weight } & \multirow{2}{*}{$\begin{array}{c}\text { Risk Ratio } \\
\text { M-H, Fixed, } 95 \% \mathrm{Cl} \\
\end{array}$} & \multirow{2}{*}{\multicolumn{3}{|c|}{$\begin{array}{c}\text { Risk Ratio } \\
\text { M-H, Fixed, } 95 \% \mathrm{Cl} \\
\end{array}$}} \\
\hline & Events & Total & Events & Total & & & & & \\
\hline Cozier et al 2015 & 315 & 32513 & 139 & 18939 & $43.0 \%$ & $1.32[1.08,1.61]$ & & 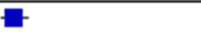 & \\
\hline Maria et al 2015 & 39 & 20541 & 101 & 54467 & $13.5 \%$ & $1.02[0.71,1.48]$ & & - & \\
\hline Orianne et al 2018 & 165 & 345 & 97 & 345 & $23.7 \%$ & $1.70[1.39,2.08]$ & & 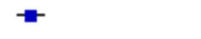 & \\
\hline Ungprasert et al 2016 & 232 & 345 & 81 & 345 & $19.8 \%$ & $2.86[2.34,3.51]$ & & $\rightarrow$ & \\
\hline Total $(95 \% \mathrm{Cl})$ & & 53744 & & 74096 & $100.0 \%$ & $1.68[1.50,1.87]$ & & $\boldsymbol{\vartheta}$ & \\
\hline Total events & 751 & & 418 & & & & & & \\
\hline $\begin{array}{l}\text { Heterogeneity: } \mathrm{Chi}^{2}=3 \\
\text { Test for overall effect: } Z\end{array}$ & $\begin{array}{l}85, d f=3 \\
9.10(P\end{array}$ & $\begin{array}{l}(P<0.0 \\
0.0000\end{array}$ & $\begin{array}{l}0001) ; i^{2} \\
\text { 1) }\end{array}$ & $=92 \%$ & & & $0.01 \quad 0.1$ & $\begin{array}{c}10 \\
\text { Favours [control] }\end{array}$ & 100 \\
\hline
\end{tabular}

Figure 2. Meta-analysis results.

\section{Discussion}

While it is well known that obesity and high BMI are associated with poor health outcomes for patients with chronic diseases [2, 41-44] including sarcoidosis, [45-47] their role in the etiology of these chronic diseases has only recently begun to be explored. [29, 43, 48-53] Studies in the past two decades have shown that obesity is associated with an increased incidence of autoimmune diseases, and have expounded on the biological plausibility of that association. [4-10, 54, 55]

The relationship between obesity and sarcoidosis has been characterized both as "posing twin problems for patients" [47] as well as a "chicken vs. egg scenario". [29] It is well known that treatment with corticosteroids, the first line treatment option for patients with sarcoidosis can be complicated by obesity, [56-62] and that obese patients with sarcoidosis are more likely to have added health problems, decreased lung function and poorer perceived health status and health related quality of life than non-obese patients with sarcoidosis. [45, 46, 63-66] Recent epidemiological studies have reported an increased incidence of sarcoidosis in obese subjects and suggest that obesity is a risk factor for disease incidence. [5, 28-31] These studies include longitudinal cohort studies [5, $28,31,32]$ that enrolled subjects prospectively, and collected data on BMI prior to the development of sarcoidosis or initiation of corticosteroids for treatment. These studies showed that there is a $42 \%$ to 3.5 fold (RR 1.42 to 3.59 ) increased incidence of sarcoidosis in obese and overweight subjects when compared to their lean and non-obese counterparts. [5, 28, 31] In addition to their longitudinal design and evidence of temporality, they also demonstrated a graded effect of BMI on the incidence of sarcoidosis suggesting a "dose-response" relationship. [5, 28, 30, 31] Harpsøe et al [5] found a 90\% (95\% CI 1.27-2.84) increased risk of developing sarcoidosis in overweight women in the Danish National Birth Cohort and a 3.6 fold (95\% CI 2.31 to 5.57) increased risk of incidence of sarcoidosis in obese Danish women compared to those with normal BMI. Similarly, Cozier et. al. [28] found that compared to African American females with normal BMI, overweight subjects (BMI 25-29.9) had a 13\% increased incidence of sarcoidosis, obese subjects (BMI $30-34 \mathrm{~kg} / \mathrm{m}^{2}$ ) had a $31 \%$ increased incidence, and morbidly obese subjects (BMI $>35 \mathrm{~kg} / \mathrm{m}^{2}$ ) had a 55\% increased incidence of sarcoidosis. [28] These findings are replicated in the other two studies included in this analysis and lend credence to the postulation that obesity may play a role in the etiology of sarcoidosis. [30,31]

Although the etiology of sarcoidosis remains unknown, the immunological mechanisms underlying granuloma formation and disease progression have been described. [24-26, 67, 68] It is biologically plausible that obesity may play a role in the etiopathogenesis of disease by influencing the immunological mechanisms of granuloma formation.

The sarcoid granuloma is thought to result from an aberrant CD4+ Th1/Th17 immune mediated response to a yet unidentified antigen. [25, 26, 67-69] Antigen presenting cells (macrophages and dendritic cells) bind to and present this putative antigen to $\mathrm{T}$ cells via HLA class II CD4 $+\mathrm{T}$ cell receptors. [67] Activation of macrophages by this putative antigen results in release of large amounts of proinflammatory cytokines such as Tumor Necrosis Factor-alpha (TNF- $\alpha$ ), interleukin (IL)-1, and IL-6. TNF- $\alpha$ induces transformation of macrophages into epithelioid and multinucleated giant cells (MGC) and activates natural killer cells (NK cells) causing release of interferon gamma (IFN- $\gamma$ ) which in turn stimulates activated macrophages to produce several chemokines that attract $\mathrm{Th} 1 / \mathrm{Th} 17$ cells, monocytes and T-regulatory cells (Tregs) to the site of inflammation. Activated macrophages, MGC and clonal CD4+ Th1/Th17 cells constitute the core of the sarcoid granuloma with a few scattered B-cells and Tregs in the periphery. It has been suggested that an impaired immunosuppressive function of Tregs in sarcoidosis plays a role in the development of chronic persistent disease. [67, 70-73]

Adipose tissue once thought to be inert, is now known to be a metabolically active "immuno-endocrine" organ that secretes a wide variety of pro-inflammatory mediators known as adipokines (adipocytokines) that induce a chronic inflammatory state in obese subjects. $[6,74]$ The adipokines secreted in obesity include IL-6, TNF- $\alpha$, leptin and adiponectin. [74, 75] IL-6 has been associated with deregulation of the Th-17/T-reg balance in obese patients, a state known to promote autoimmunity $[74,76]$. Leptin is a potent pro-inflammatory immunomodulator that enhances the proliferation and activation of NK cells, and differentiation of naïve $T$ cells to Th1 cells. Circulating levels of leptin are directly corelated with the adipose tissue 
mass and are upregulated by TNF- $\alpha$ [6]. Leptin induces macrophages to produce increased amounts of proinflammatory cytokines (TNF- $\alpha$, IL-6 and IL-12), and has been shown to inhibit the proliferation of Treg cells. $[6,75]$ Leptin mediated inhibition of Treg cells has been proposed as a mechanism that may promote the development of chronic persistent disease in obese patients. [67, 70-73] Adiponectin is an anti-inflammatory adipokine whose levels are decreased in obesity [6, 75]. It works in concert with various resident innate and adaptive immune cells in adipose tissue to dampen the inflammatory process. $[77,78]$ It has been shown, that as adipose tissue expands, there is a progressive decline in the anti-inflammatory cytokines [79, 80] and a net gain in pro-inflammatory cytokines. The net result favors a pro-inflammatory state with increased amounts of Th- 1 cells, TNF- $\alpha$, IL- 6 , IL-12 and IFN- $\gamma$. [29, $79,80]$ This cytokine milleu represents the same cytokine milieu that initiates and drives sarcoid granuloma formation and could hypothetically account for the increased incidence of sarcoidosis in obesity.

Our study sought to provide a generalizable populationwide risk estimate for the incidence of sarcoidosis in obese and overweight subjects. It is based on epidemiologic studies and reflects all the current information available on this topic. We aggregated all available data from the studies available and conducted a meta-analysis that demonstrated an overall significant positive association between obesity and incident sarcoidosis. We found that subjects who are overweight or obese have a $68 \%$ [RR 1.68, 95\% CI 1.50 - 1.87] increased risk of developing sarcoidosis when compared to normal and underweight subjects.

Our study has several strengths. First, it includes a large number of subjects (over 243,400) with long follow-up periods (11 to 24 years) recruited from population-based studies with broad geographic representation in the US and Netherlands. Second, participants were from the two countries that have the highest incidence of sarcoidosis worldwide, and within the US, there was a broad representation of subjects from all the various regions and across a broad range of age groups. [81] Third, we included only studies with a longitudinal design and excluded case reports and review articles so as to avoid any confounding by indication.

There are however several imitations to our study. First, our study population was over $99 \%$ females and was predominantly (77\%) White/Caucasian therefore, our study results may not be generalizable to males or other racial groups that are not well represented in our study. This is a reflection of the racial, gender and geo-ethnic distribution of the cohorts included in our analysis and does not represent what is known about the current epidemiology of sarcoidosis worldwide $[19,20]$. Three of the four studies $[5,28,31]$ included in our analysis were conducted in cohorts of women and our predominant female population reflects this. It is to be noted, that these cohorts were not originally designed for the study of sarcoidosis, and so do not reflect the gender or racial distribution that has been reported for sarcoidosis. Sarcoidosis is a rare disease and there are currently no cohorts designed for the study of the disease. Secondly, although we screened a large number of studies, only four studies met eligibility criteria for inclusion in the metaanalysis. This is a small number of studies; however, it represents all the studies available in this area and speaks to the need for more studies of obesity and sarcoidosis in more representative cohorts.

In conclusion, this is the first meta-analysis of its kind. It shows that there is a $68 \%$ (RR $1.68,95 \%$ CI 1.50 to 1.87 ) increased incidence of sarcoidosis in overweight and obese subjects when compared to normal and underweight individuals. More studies are needed to further evaluate the role of obesity in the etiopathogenesis of sarcoidosis. Future studies should focus on populations with a large representation of males and other geo-ethnic groups. Studies evaluating the role of leptin and adiponectin in sarcoidosis are also needed to further explore the biologic plausibility of this association.

\section{Declaration of Conflict of Interest}

The authors declare that there is no conflict of interest.

\section{Funding}

The authors received no financial support for the research, authorship, and/or publication of this article.

\section{Acknowledgements}

We would like to acknowledge librarian Cathy Cable for her assistance and inputs in conducting a comprehensive search of articles in different databases.

\section{References}

[1] Y. C. Chooi, C. Ding, and F. Magkos, "The epidemiology of obesity," (in eng), Metabolism, vol. 92, pp. 6-10, Mar 2019, doi: 10.1016/j.metabol.2018.09.005.

[2] A. Afshin et al., "Health Effects of Overweight and Obesity in 195 Countries over 25 Years," (in eng), $N$ Engl J Med, vol. 377, no. 1, pp. 13-27, 07 2017, doi: 10.1056/NEJMoa1614362.

[3] K. M. Flegal, D. Kruszon-Moran, M. D. Carroll, C. D. Fryar, and C. L. Ogden, "Trends in Obesity Among Adults in the United States, 2005 to 2014," (in eng), JAMA, vol. 315, no. 21 , pp. 2284-91, Jun 2016, doi: 10.1001/jama.2016.6458.

[4] D. P. Symmons et al., "Blood transfusion, smoking, and obesity as risk factors for the development of rheumatoid arthritis: results from a primary care-based incident casecontrol study in Norfolk, England," (in eng), Arthritis Rheum, vol. 40, no. 11, pp. 1955-61, Nov 1997, doi: 10.1002/art.1780401106.

[5] M. C. Harpsøe et al., "Body mass index and risk of autoimmune diseases: a study within the Danish National Birth Cohort," (in eng), Int J Epidemiol, vol. 43, no. 3, pp. 843-55, Jun 2014, doi: 10.1093/ije/dyu045. 
[6] M. Versini, P. Y. Jeandel, E. Rosenthal, and Y. Shoenfeld, "Obesity in autoimmune diseases: not a passive bystander," (in eng), Autoimmun Rev, vol. 13, no. 9, pp. 981-1000, Sep 2014, doi: $10.1016 /$ j.autrev.2014.07.001.

[7] A. Stavropoulos-Kalinoglou, G. S. Metsios, Y. Koutedakis, and G. D. Kitas, "Obesity in rheumatoid arthritis," (in eng), Rheumatology (Oxford), vol. 50, no. 3, pp. 450-62, Mar 2011, doi: $10.1093 /$ rheumatology/keq266.

[8] L. H. Duntas and B. Biondi, "The interconnections between obesity, thyroid function, and autoimmunity: the multifold role of leptin," (in eng), Thyroid, vol. 23, no. 6, pp. 646-53, Jun 2013, doi: 10.1089/thy.2011.0499.

[9] W. Sterry, B. E. Strober, A. Menter, and I. P. Council, "Obesity in psoriasis: the metabolic, clinical and therapeutic implications. Report of an interdisciplinary conference and review," (in eng), Br J Dermatol, vol. 157, no. 4, pp. 649-55, Oct 2007, doi: 10.1111/j.1365-2133.2007.08068.x.

[10] A. K. Hedström, T. Olsson, and L. Alfredsson, "High body mass index before age 20 is associated with increased risk for multiple sclerosis in both men and women," (in eng), Mult Scler, vol. 18, no. 9, pp. 1334-6, Sep 2012, doi: $10.1177 / 1352458512436596$.

[11] "World Health Organization," Obesity: Preventing and Managing the Global Epidemic., vol. Geneva, Switzerland: World Health Organization, 2000.

[12] C. M. Hales, M. D. Carroll, C. D. Fryar, and C. L. Ogden, "Prevalence of Obesity Among Adults and Youth: United States, 2015-2016. NCHS data brief, No 288. 2017," ed.

[13] "Prevalence of Self-Reported Obesity Among U. S. Adults by State and Territory, BRFSS, 2018." https://www.cdc.gov/obesity/data/prevalence-maps.html (accessed October 26, 2019, 2019).

[14] "Statement on sarcoidosis. Joint Statement of the American Thoracic Society (ATS), the European Respiratory Society (ERS) and the World Association of Sarcoidosis and Other Granulomatous Disorders (WASOG) adopted by the ATS Board of Directors and by the ERS Executive Committee, February 1999," (in eng), Am J Respir Crit Care Med, vol. 160, no. 2, pp. 736-55, Aug 1999, doi: 10.1164/ajrccm.160.2. ats4-99.

[15] M. C. Iannuzzi, B. A. Rybicki, and A. S. Teirstein, "Sarcoidosis," N Engl J Med, vol. 357, no. 21, pp. 2153-65, Nov 22 2007, doi: 10.1056/NEJMra071714.

[16] R. P. Baughman et al., "Clinical characteristics of patients in a case control study of sarcoidosis," Am J Respir Crit Care Med, vol. 164, no. 10 Pt 1, pp. 1885-9, Nov 15 2001, doi: 10.1164/ajrccm.164.10.2104046.

[17] Y. C. Cozier, "Assessing the worldwide epidemiology of sarcoidosis: challenges and future directions," (in eng), Eur Respir J, vol. 48, no. 6, pp. 1545-1548, 12 2016, doi: 10.1183/13993003.01819-2016.

[18] L. E. Siltzbach et al., "Course and prognosis of sarcoidosis around the world," (in eng), Am J Med, vol. 57, no. 6, pp. 84752, Dec 1974.

[19] B. A. Rybicki, M. Major, J. Popovich, Jr., M. J. Maliarik, and M. C. Iannuzzi, "Racial differences in sarcoidosis incidence: a 5-year study in a health maintenance organization," $\mathrm{Am} \mathrm{J}$ Epidemiol, vol. 145, no. 3, pp. 234-41, Feb 11997.

[20] R. P. Baughman et al., "Sarcoidosis in America. Analysis
Based on Health Care Use," (in eng), Ann Am Thorac Soc, vol. 13, no. 8, pp. 1244-52, 08 2016, doi: 10.1513/AnnalsATS.201511-760OC.

[21] P. Brito-Zerón, B. Kostov, R. P. Baughman, and M. RamosCasals, "Geoepidemiology of Sarcoidosis," in Sarcoidosis, A Clinician's Guide, R. P. Baughman and D. Valeyre Eds., no. Section 1). USA: Elsevier, 2019, ch. 1.

[22] J. Barnard et al., "Job and industry classifications associated with sarcoidosis in A Case-Control Etiologic Study of Sarcoidosis (ACCESS)," J Occup Environ Med, vol. 47, no. 3, pp. 226-34, Mar 2005.

[23] L. S. Newman et al., "A case control etiologic study of sarcoidosis: environmental and occupational risk factors," $\mathrm{Am}$ $J$ Respir Crit Care Med, vol. 170, no. 12, pp. 1324-30, Dec 15 2004, doi: 10.1164/rccm.200402-249OC.

[24] E. S. Chen and D. R. Moller, "Etiology of sarcoidosis," (in eng), Clin Chest Med, vol. 29, no. 3, pp. 365-77, vii, Sep 2008, doi: 10.1016/j.ccm.2008.03.011.

[25] S. Saidha, E. S. Sotirchos, and C. Eckstein, "Etiology of sarcoidosis: does infection play a role?," (in eng), Yale J Biol Med, vol. 85, no. 1, pp. 133-41, Mar 2012.

[26] D. R. Moller et al., "Genetic, Immunologic, and Environmental Basis of Sarcoidosis," Ann Am Thorac Soc, vol. 14, no. Supplement_6, pp. S429-S436, Dec 2017, doi: 10.1513/AnnalsATS.201707-565OT.

[27] J. P. Cremers et al., "Body composition profiling in a Dutch sarcoidosis population," (in eng), Sarcoidosis Vasc Diffuse Lung Dis, vol. 30, no. 4, pp. 289-99, Dec 2013.

[28] Y. C. Cozier, P. F. Coogan, P. Govender, J. S. Berman, J. R. Palmer, and L. Rosenberg, "Obesity and weight gain in relation to incidence of sarcoidosis in US black women: data from the Black Women's Health Study," (in eng), Chest, vol. 147, no. 4, pp. 1086-1093, Apr 2015, doi: 10.1378/chest.14-1099.

[29] Y. C. Cozier, P. Govender, and J. S. Berman, "Obesity and sarcoidosis: consequence or contributor?," (in eng), Curr Opin Pulm Med, vol. 24, no. 5, pp. 487-494, 09 2018, doi: 10.1097/MCP.0000000000000503.

[30] P. Ungprasert, C. S. Crowson, and E. L. Matteson, "Smoking, obesity and risk of sarcoidosis: A population-based nested case-control study," (in eng), Respir Med, vol. 120, pp. 87-90, 11 2016, doi: 10.1016/j.rmed.2016.10.003.

[31] O. Dumas, K. M. Boggs, Y. C. Cozier, M. J. Stampfer, and C. A. Camargo, "Prospective study of body mass index and risk of sarcoidosis in US women," (in eng), Eur Respir J, vol. 50, no. 4, 10 2017, doi: 10.1183/13993003.01397-2017.

[32] J. Olsen et al., "The Danish National Birth Cohort--its background, structure and aim," (in eng), Scand J Public Health, vol. 29, no. 4, pp. 300-7, Dec 2001.

[33] Y. C. Cozier, J. S. Berman, J. R. Palmer, D. A. Boggs, D. M. Serlin, and L. Rosenberg, "Sarcoidosis in black women in the United States: data from the Black Women's Health Study," (in eng), Chest, vol. 139, no. 1, pp. 144-50, Jan 2011, doi: 10.1378/chest.10-0413.

[34] O. Dumas, L. Abramovitz, A. S. Wiley, Y. C. Cozier, and C. A. Camargo, "Epidemiology of Sarcoidosis in a Prospective Cohort Study of U. S. Women," (in eng), Ann Am Thorac Soc, vol. 13, no. 1, pp. 67-71, Jan 2016, doi: 10.1513/AnnalsATS.201508-568BC. 
[35] T. Izumi, "Symposium: Population differences in clinical features and prognosis of sarcoidosis throughout the world. International survey report.," Sarcoidosis, vol. 9, pp. S105S110, 1992.

[36] U. Costabel, T. E. Wessendorf, and F. Bonella, "[Epidemiology and Clinical Presentation of Sarcoidosis]," Klin Monbl Augenheilkd, vol. 234, no. 6, pp. 790-795, Jun 2017, doi: 10.1055/s-0042-105569. Epidemiologie und klinisches Erscheinungsbild der Sarkoidose.

[37] M. A. Judson, A. D. Boan, and D. T. Lackland, "The clinical course of sarcoidosis: presentation, diagnosis, and treatment in a large white and black cohort in the United States," (in eng), Sarcoidosis Vasc Diffuse Lung Dis, vol. 29, no. 2, pp. 119-27, Oct 2012

[38] B. A. Rybicki et al., "Familial aggregation of sarcoidosis. A case-control etiologic study of sarcoidosis (ACCESS)," Am J Respir Crit Care Med, vol. 164, no. 11, pp. 2085-91, Dec 1 2001, doi: 10.1164/ajrccm.164.11.2106001.

[39] T. Morimoto et al., "Epidemiology of sarcoidosis in Japan," (in eng), Eur Respir J, vol. 31, no. 2, pp. 372-9, Feb 2008, doi: 10.1183/09031936.00075307.

[40] B. Jayakrishnan et al., "Clinical features of Sarcoidosis in Oman: A report from the Middle East region," Sarcoidosis Vasc Diffuse Lung Dis, vol. 33, no. 3, pp. 201-208, Oct 72016.

[41] G. A. Bray et al., "The Science of Obesity Management: An Endocrine Society Scientific Statement," (in eng), Endocr Rev, vol. 39, no. 2, pp. 79-132, 04 2018, doi: 10.1210/er.201700253 .

[42] M. D. Jensen et al., "2013 AHA/ACC/TOS guideline for the management of overweight and obesity in adults: a report of the American College of Cardiology/American Heart Association Task Force on Practice Guidelines and The Obesity Society," (in eng), $J$ Am Coll Cardiol, vol. 63, no. 25 Pt B, pp. 2985-3023, Jul 2014, doi: 10.1016/j.jacc.2013.11.004.

[43] A. Mohan, J. Grace, B. R. Wang, and N. Lugogo, "The Effects of Obesity in Asthma," (in eng), Curr Allergy Asthma Rep, vol. 19, no. 10, p. 49, Sep 2019, doi: 10.1007/s11882-019-0877-z.

[44] G. Klepaker et al., "Influence of Obesity on Work Ability, Respiratory Symptoms, and Lung Function in Adults with Asthma," (in eng), Respiration, pp. 1-9, Aug 2019, doi: $10.1159 / 000502154$

[45] B. S. Gvozdenovic et al., "Effect of obesity on patientreported outcomes in sarcoidosis," (in eng), Int J Tuberc Lung Dis, vol. 17, no. 4, pp. 559-64, Apr 2013, doi: 10.5588/ijtld.12.0665.

[46] M. Fleischer, A. Hinz, E. Brähler, H. Wirtz, and A. BosseHenck, "Factors associated with fatigue in sarcoidosis," (in eng), Respir Care, vol. 59, no. 7, pp. 1086-94, Jul 2014, doi: 10.4187/respcare.02080.

[47] A. Baydur, "Sarcoidosis and obesity: twin problems for the patient," (in eng), Int J Tuberc Lung Dis, vol. 17, no. 4, p. 431, Apr 2013, doi: 10.5588/ijtld.13.0119.

[48] K. Mizuta, A. Matoba, S. Shibata, E. Masaki, and C. W. Emala, "Obesity-induced asthma: Role of free fatty acid receptors," (in eng), Jpn Dent Sci Rev, vol. 55, no. 1, pp. 103107, Nov 2019, doi: 10.1016/j.jdsr.2019.07.002.
[49] P. F. Coogan, J. R. Palmer, G. T. O'Connor, and L. Rosenberg, "Body mass index and asthma incidence in the Black Women's Health Study," (in eng), J Allergy Clin Immunol, vol. 123, no. 1, pp. 89-95, Jan 2009, doi: 10.1016/j.jaci.2008.09.040.

[50] S. Xu, F. D. Gilliland, and D. V. Conti, "Elucidation of causal direction between asthma and obesity: a bi-directional Mendelian randomization study," (in eng), Int $J$ Epidemiol, vol. 48, no. 3, pp. 899-907, Jun 2019, doi: 10.1093/ije/dyz070.

[51] J. Costa-Font and J. Gil, "Obesity and the incidence of chronic diseases in Spain: a seemingly unrelated probit approach," (in eng), Econ Hum Biol, vol. 3, no. 2, pp. 188-214, Jul 2005, doi: 10.1016/j.ehb.2005.05.004.

[52] E. Dal Grande, T. Gill, L. Wyatt, C. R. Chittleborough, P. J. Phillips, and A. W. Taylor, "Population attributable risk (PAR) of overweight and obesity on chronic diseases: South Australian representative, cross-sectional data, 2004-2006," (in eng), Obes Res Clin Pract, vol. 3, no. 3, pp. I-IV, Aug 2009, doi: 10.1016/j.orcp.2009.03.004.

[53] M. Granata, E. Skarmoutsou, C. Trovato, G. A. Rossi, M. C. Mazzarino, and F. D'Amico, "Obesity, Type 1 Diabetes, and Psoriasis: An Autoimmune Triple Flip," (in eng), Pathobiology, vol. 84, no. 2, pp. 71-79, 2017, doi: 10.1159/000447777.

[54] K. Van Raemdonck, S. Umar, Z. Szekanecz, R. K. Zomorrodi, and S. Shahrara, "Impact of obesity on autoimmune arthritis and its cardiovascular complications," (in eng), Autoimmun Rev, vol. 17, no. 8, pp. 821-835, Aug 2018, doi: 10.1016/j.autrev.2018.02.007.

[55] E. Gremese, B. Tolusso, M. R. Gigante, and G. Ferraccioli, "Obesity as a risk and severity factor in rheumatic diseases (autoimmune chronic inflammatory diseases)," (in eng), Front Immunol, vol. 5, p. 576, 2014, doi: 10.3389/fimmu.2014.00576.

[56] G. J. Gibson et al., "British Thoracic Society Sarcoidosis study: effects of long term corticosteroid treatment," (in eng), Thorax, vol. 51, no. 3, pp. 238-47, Mar 1996, doi: 10.1136/thx.51.3.238.

[57] R. P. Baughman, H. Nunes, N. J. Sweiss, and E. E. Lower, "Established and experimental medical therapy of pulmonary sarcoidosis," (in eng), Eur Respir J, vol. 41, no. 6, pp. 142438, Jun 2013, doi: 10.1183/09031936.00060612.

[58] S. H. Beegle, K. Barba, R. Gobunsuy, and M. A. Judson, "Current and emerging pharmacological treatments for sarcoidosis: a review," (in eng), Drug Des Devel Ther, vol. 7, pp. 325-38, 2013, doi: 10.2147/DDDT. S31064.

[59] A. C. Schutt, W. M. Bullington, and M. A. Judson, "Pharmacotherapy for pulmonary sarcoidosis: a Delphi consensus study," (in eng), Respir Med, vol. 104, no. 5, pp. 717-23, May 2010, doi: 10.1016/j.rmed.2009.12.009.

[60] M. A. Judson, "Corticosteroids in Sarcoidosis," (in eng), Rheum Dis Clin North Am, vol. 42, no. 1, pp. 119-35, ix, Feb 2016, doi: 10.1016/j.rdc.2015.08.012.

[61] N. A. Khan et al., "Toxicity risk from glucocorticoids in sarcoidosis patients," (in eng), Respir Med, vol. 132, pp. 9-14, Nov 2017, doi: 10.1016/j.rmed.2017.09.003.

[62] D. Huscher et al., "Dose-related patterns of glucocorticoidinduced side effects," (in eng), Ann Rheum Dis, vol. 68, no. 7, pp. 1119-24, Jul 2009, doi: 10.1136/ard.2008.092163. 
[63] R. P. Baughman et al., "Use of fluticasone in acute symptomatic pulmonary sarcoidosis," (in eng), Sarcoidosis Vasc Diffuse Lung Dis, vol. 19, no. 3, pp. 198-204, Oct 2002.

[64] M. A. Judson, H. Chaudhry, A. Louis, K. Lee, and R. Yucel, "The effect of corticosteroids on quality of life in a sarcoidosis clinic: the results of a propensity analysis," (in eng), Respir Med, vol. 109, no. 4, pp. 526-31, Apr 2015, doi: 10.1016/j.rmed.2015.01.019.

[65] A. N. Aggarwal, K. K. Sahu, and D. Gupta, "Fatigue and health-related quality of life in patients with pulmonary sarcoidosis treated by oral Corticosteroids," (in eng), Sarcoidosis Vasc Diffuse Lung Dis, vol. 33, no. 2, pp. 124-9, Aug 2016.

[66] M. Savas et al., "Systematic Evaluation of Corticosteroid Use in Obese and Non-obese Individuals: A Multi-cohort Study," (in eng), Int J Med Sci, vol. 14, no. 7, pp. 615-621, 2017, doi: 10.7150/ijms. 19213 .

[67] C. E. Broos, M. van Nimwegen, H. C. Hoogsteden, R. W. Hendriks, M. Kool, and B. van den Blink, "Granuloma formation in pulmonary sarcoidosis," (in eng), Front Immunol, vol. 4, p. 437, Dec 2013, doi: 10.3389/fimmu.2013.00437.

[68] A. K. Gerke and G. Hunninghake, "The immunology of sarcoidosis," (in eng), Clin Chest Med, vol. 29, no. 3, pp. 37990, vii, Sep 2008, doi: 10.1016/j.ccm.2008.03.014.

[69] P. Sakthivel and D. Bruder, "Mechanism of granuloma formation in sarcoidosis," Curr Opin Hematol, vol. 24, no. 1, pp. 59-65, Jan 2017, doi: 10.1097/MOH.0000000000000301.

[70] C. Taflin et al., "FoxP3+ regulatory $\mathrm{T}$ cells suppress early stages of granuloma formation but have little impact on sarcoidosis lesions," (in eng), Am J Pathol, vol. 174, no. 2, pp. 497-508, Feb 2009, doi: 10.2353/ajpath.2009.080580.

[71] M. Miyara et al., "The immune paradox of sarcoidosis and regulatory T cells," (in eng), $J$ Exp Med, vol. 203, no. 2, pp. 359-70, Feb 2006, doi: 10.1084/jem.20050648.

[72] G. Rappl et al., "Regulatory T cells with reduced repressor capacities are extensively amplified in pulmonary sarcoid lesions and sustain granuloma formation," (in eng), Clin Immunol, vol. 140, no. 1, pp. 71-83, Jul 2011, doi: 10.1016/j.clim.2011.03.015.
[73] K. A. Oswald-Richter et al., "Reversal of global CD4+ subset dysfunction is associated with spontaneous clinical resolution of pulmonary sarcoidosis," (in eng), J Immunol, vol. 190, no. 11, pp. 5446-53, Jun 2013, doi: 10.4049/jimmunol.1202891.

[74] H. Cao, "Adipocytokines in obesity and metabolic disease," (in eng), J Endocrinol, vol. 220, no. 2, pp. T47-59, Feb 2014, doi: 10.1530/JOE-13-0339.

[75] A. Stofkova, "Leptin and adiponectin: from energy and metabolic dysbalance to inflammation and autoimmunity," (in eng), Endocr Regul, vol. 43, no. 4, pp. 157-68, Oct 2009.

[76] M. Ahmed and S. L. Gaffen, "IL-17 in obesity and adipogenesis," (in eng), Cytokine Growth Factor Rev, vol. 21, no. 6, pp. 449-53, Dec 2010, doi: 10.1016/j.cytogfr.2010.10.005.

[77] S. Nishimura et al., "Adipose Natural Regulatory B Cells Negatively Control Adipose Tissue Inflammation," (in eng), Cell Metab, vol. 18, no. 5, pp. 759-766, Nov 2013, doi: 10.1016/j.cmet.2013.09.017.

[78] M. Rakhshandehroo, E. Kalkhoven, and M. Boes, "Invariant natural killer $\mathrm{T}$ cells in adipose tissue: novel regulators of immune-mediated metabolic disease," (in eng), Cell Mol Life Sci, vol. 70, no. 24, pp. 4711-27, Dec 2013, doi: 10.1007/s00018-013-1414-1.

[79] T. D. Kanneganti and V. D. Dixit, "Immunological complications of obesity," (in eng), Nat Immunol, vol. 13, no. 8, pp. 707-12, Jul 2012, doi: 10.1038/ni.2343.

[80] H. S. Schipper, B. Prakken, E. Kalkhoven, and M. Boes, "Adipose tissue-resident immune cells: key players in immunometabolism," (in eng), Trends Endocrinol Metab, vol. 23, no. 8, pp. 407-15, Aug 2012, doi: 10.1016/j.tem.2012.05.011.

[81] E. V. Arkema and Y. C. Cozier, "Epidemiology of sarcoidosis: current findings and future directions," (in eng), Ther Adv Chronic Dis, vol. 9, no. 11, pp. 227-240, Nov 2018, doi: 10.1177/2040622318790197.

[82] P. Ungprasert, D. A. Wetter, C. S. Crowson, and E. L. Matteson, "Epidemiology of cutaneous sarcoidosis, 19762013: a population-based study from Olmsted County, Minnesota," (in eng), J Eur Acad Dermatol Venereol, vol. 30, no. 10, pp. 1799-1804, Oct 2016, doi: 10.1111/jdv.13760. 